Goldschmidt 2021 Abstract

https://doi.org/10.7185/gold2021.5682

\section{Dissolved oxygen stable isotopes in groundwater: a new tracer of biogeochemical reactivity for the underground Critical Zone}

\author{
IVAN-DAVID OSORIO-LEON ${ }^{1}$, DR. ELIOT CHATTON ${ }^{2}$, \\ MARLENE DORDONI ${ }^{3}$, DAVID PIATKA ${ }^{3}$, TANGUY LE \\ BORGNE $^{4}$ AND CAMILLE BOUCHEZ ${ }^{4}$
}

${ }^{1}$ Univ Rennes, CNRS, Géosciences Rennes, UMR 6118

${ }^{2}$ CNRS UMR6118

${ }^{3}$ GeoZentrum Nordbayern, Friedrich- Alexander-University

${ }^{4}$ Univ Rennes - CNRS

Presenting Author: ivan-david.osorio-leon@univ-rennes1.fr

The persistence of dissolved oxygen (DO) in deep groundwater sustains microbial life and biogeochemical reactivity, with potential impacts on large scale nutrient cycling. In aquifers, DO is often heterogeneous and intermittent, but the driving factors of its spatial and temporal distributions remain poorly constrained. This study aims to identify the reactive processes controlling DO dynamics in a fractured-bedrock catchment in Brittany, characterized by strong surfacegroundwater connectivity, rapid hydrologic response and deep microbial hot-spots.

Oxygen stable isotopes of DO $\left(\delta^{18} \mathrm{O}_{\mathrm{DO}}\right)$ and of the water molecule $\left(\delta^{18} \mathrm{O}_{\mathrm{H} 2 \mathrm{O}}\right)$, major gases, chlorofluorocarbons (CFCs) and major cations and anions were analyzed on rainwater and on groundwater sampled from ten $150 \mathrm{~m}$-deep piezometers located in recharge and discharge zones of the catchment. We show that DO concentrations decrease with increasing water residence time while $\delta^{18} \mathrm{O}_{\mathrm{DO}}$ signatures show two different trends depending on DO concentrations. Decreasing DO concentrations ranging from $1.5-10 \mathrm{mg} / \mathrm{L}$ are associated with an unexpected depletion of $\delta^{18} \mathrm{O}_{\mathrm{DO}}$. Conversely, DO concentrations below $1.5 \mathrm{mg} / \mathrm{L}$ (the socalled microaerobic range) are associated with a consistent increase of the $\delta^{18} \mathrm{O}_{\mathrm{DO}}$. Our results reveal a shift in reactive processes controlling DO dynamics and $\delta^{18} \mathrm{O}_{\mathrm{DO}}$ at catchment scale.

Chemical data as well as laboratory reactivity batch experiments indicate that the abiotic oxidation of dissolved iron ( $\mathrm{Fe}(\mathrm{II}))$ is the main reactive process consuming oxygen at high DO concentrations. However, this process is unlikely to be responsible for $\delta^{18} \mathrm{O}_{\mathrm{DO}}$ depletion, as it rather produces a $\delta^{18} \mathrm{O}_{\mathrm{DO}}$ enrichment effect. Circumstantial data on $\delta^{18} \mathrm{O}_{\mathrm{H} 2 \mathrm{O}}$ might explain the $\delta^{18} \mathrm{O}_{\mathrm{DO}}$ depletion through isotopic equilibrium exchanges between DO and water molecules. Nevertheless, other possible processes such as diffusion and exchanges with other oxygenbearing species might also be at play and have not been explored. On the other hand, the observed enrichment in $\delta^{18} \mathrm{O}_{\mathrm{DO}}$ at low DO concentrations clearly reflects DO consumption by the activity of microaerobic iron-oxidizing bacteria (FeOB) (Figure 1).

The present study shows a spatial heterogeneity of biogeochemical reactive processes controlled by DO concentrations. DO stable isotopes proved useful to unravel biotic and abiotic processes at stake in the deep critical zone with possible applications for the assessment of primary production of deep biomass.

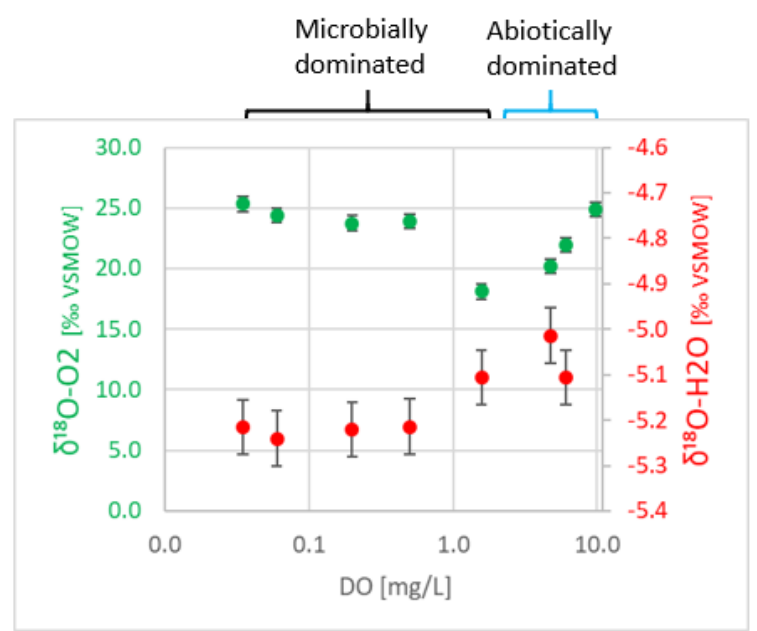

Figure 1. Evolution of stable oxygen isotopes of DO and water as a function of DO concentrations. 